Published in final edited form as:

Pediatrics. 2010 June ; 125(6): . doi:10.1542/peds.2009-2635.

\title{
Child Health Research Funding and Policy: Imperatives and Investments for a Healthier World
}

\author{
William W. Hay Jr, MDa, Daniel P. Gitterman, PhD $^{b}$, David A. Williams, MD ${ }^{c, d}$, George J. \\ Dover, $\mathbf{M D}^{\mathrm{e}}$, Theodore C. Sectish, MD ${ }^{\mathrm{f}, \mathrm{g}}$, and Mark R. Schleiss, MD
}

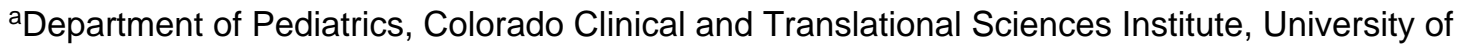
Colorado School of Medicine, Aurora, Colorado bepartment of Public Policy, University of North Carolina, Chapel Hill, North Carolina 'Division of Hematology/Oncology, Department of Pediatrics, Harvard Medical School, Boston, Massachusetts ${ }^{\mathrm{d}}$ Translational Research, Children's Hospital Boston, Boston, Massachusetts ${ }^{\mathrm{e}}$ Department of Pediatrics, Johns Hopkins University School of Medicine, Baltimore, Maryland 'Boston Combined Residency Program in Pediatrics, Children's Hospital Boston and Harvard Medical School, Boston, Massachusetts 9Federation of Pediatric Organizations, Boston, Massachusetts henter for Infectious Diseases and Microbiology Translational Research, Department of Pediatrics, University of Minnesota Medical School, Minneapolis, Minnesota

\section{Abstract}

Although pediatric research enjoyed significant benefits during the National Institutes of Health (NIH) doubling era, the proportion of the NIH budget devoted to the pediatric-research portfolio has declined overall. In light of this declining support for pediatric biomedical research, the Federation of Pediatric Organizations held a topic symposium at the 2009 Pediatric Academic Societies annual meeting as a forum for discussion of the past and future states of funding, the rationale for directing public funds toward the understanding of child health and disease, and new programs and paradigms for promoting child health research. This report of the symposium is intended to disseminate more broadly the information presented and conclusions discussed to encourage those in the child health research community to exert influence with policy makers to increase the allocation of national funding for this underfunded area.

Copyright $(92010$ by the American Academy of Pediatrics

Address correspondence to William W. Hay Jr, MD, University of Colorado Denver F441, Perinatal Research Facility, 13240 E 23rd Ave, Aurora, CO 80045. bill.hay@ucdenver.edu.

FINANCIAL DISCLOSURE: The authors have indicated they have no financial relationships relevant to this article to disclose.

The Physician Shortage Problem is Only 15 Years Away: The new federal health-care law will allow more people to access affordable health care, but there may not be enough doctors to provide that care. According to an article in The Wall Street Journal (Sataline S and Wong SS, April 12, 2010), we could be short as many as 150000 physicians in the next 15 years (based on data obtained from the Association of American Medical Colleges) even with an effort to increase the number of US doctors through new medical schools and increased class sizes of existing schools. The highest demand will be for primary-care physicians. While there may be more future physicians in the medical school pipelines, there has yet to be a proportionate increase in residency positions to accommodate these higher numbers due to a cap on Medicare funding (which pays for residency training). This cap currently prevents an increase in the available post-graduate training positions in proportion to the increasing numbers of students. Unfortunately the new health-care law does not have a provision to increase funded residency slots but can shift funds from unfilled slots into other residency programs that might increase their number of residency slots for primary care specialties (including pediatrics).

Noted by JFL, MD

Reprints Information about ordering reprints can be found online: http://www.pediatrics.org/misc/reprints.shtml 


\title{
Keywords
}

child heath; pediatrics; pediatric-research funding; National Institutes of Health, NIH; Eunice Kennedy Shriver National Institute of Child Health and Development, NICHD; Federation of Pediatric Organizations, FOPO

\begin{abstract}
Although pediatric research enjoyed significant benefits during the National Institutes of Health (NIH) doubling era, the proportion of the NIH budget devoted to the pediatricresearch portfolio has declined overall. The Federation of Pediatric Organizations held a topic symposium at the 2009 Pediatric Academic Societies annual meeting as a forum for discussion of the past and future states of funding, the rationale for directing public funds toward the understanding of child health and disease, and new programs and paradigms for promoting child health research. Although important new initiatives have been focused on a range of both rare and common pediatric conditions, our main conclusion is that there is a need to increase the future support for pediatric biomedical research and to expand the number of opportunities for advancement in scientific investigations and care for children. Pediatricians will need to offer new conceptual arguments and evidence about the longerterm benefits for tomorrow's adults of today's investment in the health and well-being of our pediatric populations.
\end{abstract}

\section{CHILD HEALTH RESEARCH FUNDING: IS THAT SINKING FEELING OVER? THE DECLINING INVESTMENT IN PEDIATRIC RESEARCH}

Dr Gitterman focused on the declining investment in pediatric-research funding and its failure to keep up with recent congressional attempts to promote research during the NIH budget-doubling period as well as the most recent period in which the Bush administration kept NIH funding relatively constant despite ongoing inflation.1 Such declines occurred despite a continuing awareness in Congress that there was inadequate pediatric-research support. Moreover, as pointed out by Dr Gitterman, Congress has acknowledged in the past that research on children is highly beneficial to promoting not only their health but that of the national population. For example, in 1995 Congress was "concerned that inadequate attention and resources are devoted to pediatric research conducted and supported by NIH" (H.R. report No. 209, 104th Congress, 1st session, 80-81, 1995) and that Congress does indeed "recognize the substantial benefits that biomedical research offers to the health and well-being of our Nation's children.... and intends to work with the NIH Director as it explores ways to strengthen the NIH's capacity to support and encourage extramural pediatric research" (Senate report No. 145, 104th Congress, 1st session, 112, 1995).

In response, Congress established the Pediatric Research Initiative (PRI) (as part of the 2000 Children's Health Act) to increase support for pediatric research, strengthen collaborative efforts among NIH institutes and centers, speed the development of pediatric clinical drug trials, and invest in training pediatric researchers. As part of the PRI, Congress authorized $\$ 50$ million for the NIH Office of the Director to support the PRI in fiscal-year 2001. The Children's Health Act became effective after the fiscal-year 2001 appropriations cycle, but unfortunately, no future fiscal year's appropriations included PRI funding. Dr Gitterman highlighted the NIH's overall budget and its pediatric-research funding across 3 time periods: before doubling (fiscal-year 1992-1997); doubling (fiscal-year 1998-2003); and after doubling (fiscal-year 2004-2009). The average annual NIH appropriations increased by $5.4 \%, 13.4 \%$, and $1.3 \%$ in each period, respectively. The average annual pediatric-research funding (actual grants, contracts, intramural research, and other mechanisms of support) increased much less, by $4.7 \%, 11.5 \%$, and $0.3 \%$ in each period, respectively. Between fiscal years 2004 and 2007, the average NIH budget increase nearly flattened, to only $1.96 \%$. 
During this period, average pediatric-research funding has dropped markedly lower, to $0.57 \%$; estimated fiscal-year 2008 pediatric funding is at $-0.5 \%$. Although NIH appropriations and pediatric-research funding increased in nominal amounts, the proportion devoted to pediatrics has remained flat, as it has done since fiscal-year 1992 (Fig 1).2

\section{PEDIATRIC RESEARCH: EMERGING OPPORTUNITIES FOR CHILD HEALTH RESEARCH FUNDING THROUGH THE NIH AND THE EUNICE KENNEDY SHRIVER NATIONAL INSTITUTE OF CHILD HEALTH AND DEVELOPMENT}

Dr Duane Alexander, director of the Eunice Kennedy Shriver National Institute of Child Health and Development (NICHD), discussed the many opportunities for pediatric research at the NICHD that are funded, first noting how the NIH and NICHD have organized their research agenda. An overarching goal has been to build on established infrastructure, sustaining and modernizing successful, long-standing programs, and developing coordinated and shared pediatric resources. These approaches include creation of virtual networks, speeding translation of new discoveries into clinical practice, growing multidisciplinary teams and networks, pioneering studies as a foundation for future research, and capitalizing on opportunities by using American Recovery and Reinvestment Act funds. The NICHD supports more than 20 network and center programs targeted directly to pediatric research (Table 1). The NICHD also supports more than 30 additional active programs of solicited research targeted to pediatrics.

Regarding infrastructure, the NICHD supports a large variety of research training programs for pediatricians, including Child Health Research Career Development Awards ( $>600$ physician-scientists trained over the past 21 years, two-thirds of whom continued in research careers and half of whom received subsequent NIH funding) and the Pediatric Scientist Development Program (155 pediatricians trained over the past 20 years, three-fifths of whom continued in research careers and half of whom received subsequent NIH funding). Recently, the NICHD introduced the Pediatric Critical Care Career Development Program, which has trained 15 critical care pediatricians in the past 5 years. More than 2500 pediatricians have taken advantage of the NIH loan-repayment program targeted specifically to pediatrics, covering $26 \%$ of all NIH extramural loan-repayment applications. Pediatric loan-repayment applicants have comparable success rates to other loan-repayment applicants. Overall, loan-repayment recipients are more likely to remain in research careers than similar unfunded applicants.

Regarding the inclusion of children in research, NIH policy requires investigators to include children in clinical research unless they can justify not doing so. Across the NIH, $62.3 \%$ of human-subjects grants included children (fiscal-year 2007). Preliminary analyses showed that $87 \%$ of NICHD grants included children younger than 21 years, and $65 \%$ included children younger than 18 .

Regarding new programs at the NICHD, Dr Alexander commented specifically on the Pediatric Pharmacology Research Units (PPRUs), which have successfully developed infrastructure and conducted cooperative multisite clinical trials, as well as enhanced training opportunities in pediatric pharmacology. The PPRUs focus on developmental pharmacology to understand developmentally related changes in metabolism and response to drugs, develop predictive models to evaluate response/toxicity for pediatric subpopulations, develop and validate pharmacokinetic/pharmacodynamic assessments to help evaluate these responses, and facilitate opportunities to participate in centers and a clinical trials network dedicated to pediatric pharmacology. Related to the PPRU infrastructure, Congress passed 
the Best Pharmaceuticals for Children Act to conduct studies of off-patent or on-patent drugs or biological agents for unmet children's therapeutic health needs.

Among growing research opportunities through the NIH, Dr Alexander discussed the Pediatric Medical Device Safety and Improvement Act, which stimulates research to develop devices for pediatric use to help prevent, diagnose, mitigate, or cure disorders. The NICHD cooperates through a trans-NIH group that works with the Agency for Healthcare Research and Quality and the Food and Drug Administration to develop a research plan and report to Congress. New opportunities include academic/industry collaborations and partnerships to develop devices, response to NIH institute- and center-specific and transNIH initiatives (eg, catheters for newborns), and translation of a range of devices for adult diseases and conditions to pediatric diseases and conditions.

Dr Alexander also noted that the NICHD has supported pediatric components in the National Center for Research Resources Clinical Translational Science Award (CTSA) program, particularly the CTSA Consortium Child Health Oversight Committee. He noted many opportunities for collaboration, including a distributed biobank for rare pediatric diseases, support for pediatric medical devices, informatics, a national database for translational research, outcome-measures development, and external partnership with the Pediatric Academic Societies annual meeting.

Dr Alexander also discussed the growing number of multidisciplinary research programs. The Newborn Screening Translation Research Network builds on Health Resources and Services Administration and Centers for Disease Control data to develop and test new assays for individual conditions by using common screening platforms; systematically introduce tests nationwide; and develop new treatments for conditions once assays are available.

Dr Alexander then discussed the National Children's Study (NCS), the largest long-term study of children's health and development ever conducted, which would follow approximately 100000 children and families from before birth to the age of 21 . The NCS was established under the rationale that children are especially vulnerable to adverse environmental exposures, existing research is too limited in size and scope, and life-course (longitudinal) designs are needed to correctly link multiple exposures and multiple outcomes. Many collaborative research opportunities may be available through the NCS, including add-on studies and planned analyses of core hypotheses and public-use data sets by multiple investigators.

Last, Dr Alexander noted the many pediatric-research opportunities under the American Recovery and Reinvestment Act, including Challenge Grants, Grand Opportunity Grants, Administrative Supplements, Student/Teacher Supplements, Competitive Revisions, Autism requests for applications, 2-year research project grants, expanded pay lines, extramural research facilities, and other opportunities still being created in specific areas. High-priority topics that are relevant to children have included alcohol and adolescents, asthma in children, autism, childhood cancer, childhood obesity, childhood onset of mental disorders, cleft lip and palate, hearing devices in children, immunization compliance, learning disabilities, neonatal exposure to drugs of abuse, pediatric cardiology, pediatric medical devices, pediatric rheumatic and musculoskeletal disease, science education, youth and HIV, and many more. 


\section{NEW PARADIGMS IN CHILD HEALTH RESEARCH FUNDING: THE RATIONALE FOR THE PEDIATRIC RESEARCH CONSORTIA BILL}

Although the NICHD remains extremely active and successful in providing research opportunities for investigators, Dr Williams noted that the pediatric physician-scientist workforce remains small and is not growing substantially. As reported recently by the National Association of Children's Hospitals and Related Institutions, the number of many pediatric subspecialists, a surrogate for physician-scientists, is still critically low in many academic health centers. 3

Many obstacles confront investigators who seek to develop new treatments for pediatric diseases. 4 The time delay for application of new drugs to pediatric diseases is excessive, in part because of a lack of translational research and early-phase, controlled therapeutic trials in children. There is increased difficulty in carrying out translational research in children because of smaller patient numbers, reluctance of parents to enroll children in "experimental" trials, 5 and the ethical dilemmas of enrolling children in phase I trials. 6 There also is insufficient networking of pediatric programs for both basic research and translational/clinical trials, particularly those that are focused on the pediatric antecedents to adult diseases, which exert major costs on society. 7

Cutting-edge research in the post-genomics era requires large-scale infrastructure for applications in translational and clinical research. A prime example is the NIH National Cancer Institute Comprehensive Cancer Program, which fosters innovative applications of basic research to translational/clinical research and clinical trials by supporting infrastructure required for innovative, collaborative, and multidisciplinary research focused on cancer. To develop a similar approach for pediatric research, Dr Williams and others established the National Pediatric Research Consortia to develop the Pediatric Research Consortium Establishment Act via congressional mandate (ie, new money). As such, it would become a mechanism to both enhance NIH funding of childhood diseases and increase efficiency collaborative and translational research consistent with the NIH roadmap. The development process has included general support of concept from all groups involved, including the executive committee of the Association of Medical School Pediatric Department Chairs, the American Pediatric Society and Society for Pediatric Research councils, the National Association of Children's Hospitals and Related Institutions, and the American Academy of Pediatrics.

Specific legislation requesting authorization of the Pediatric Research Consortia Act was introduced in the spring of 2009 as Senate Bill 353 and House of Representatives Bill 758 and is currently under legislative review. The purposes of the Pediatric Research Consortium Establishment Act are to strengthen the pediatric-research portfolio of the NIH, establish priorities for pediatric research; ensure adequacy of translational research, and facilitate "spoke-and-wheel" conformation to include centers with smaller patient populations. The act establishes the National Pediatric Research Program under the director of the NIH. It could and should leverage support from multiple institutes for additional requests for applications in disease-specific areas and strengthen justification and opportunity for new money for pediatric research. Another major goal is to increase interinstitutional networking. The consortium program is complementary to the NCS and major training programs in pediatrics and also would complement the goals of CTSAs by emphasizing basic translational research.

The act envisions 20 large centers or "national pediatric research and demonstration centers" that support their own and collaborative smaller programs in a geographic region. These centers will be better able to support basic, translational, and clinical research and training 
and demonstrate use of new diagnostics and therapies in the pediatric population. Funded centers would provide excellent opportunities for transdisciplinary, mechanistic, and translational approaches aimed at new discoveries, diagnoses, and therapies. The longitudinal funding of expensive but necessary cores and shared services will support stateof-the-art basic and translational research. This support will provide an enabling "foundation" to enhance the quality and timeliness of research into pediatric diseases, speed the development of new clinical trials, increase the competitiveness of pediatric researchers across multiple funding mechanisms (including all institutes at the NIH), and ultimately speed development of new therapies for childhood diseases.

\section{INVESTMENT IN CHILD HEALTH RESEARCH: SMART MONEY, WELL SPENT-HOW RESEARCH IN EARLY LIFE DISORDERS PAYS HUGE DIVIDENDS IN ADULT HEALTH}

Dr Dover discussed how investment in pediatric research in early life pays huge dividends for the entire population over its life span. Over the past 20 to 30 years the United States has led other Western countries in per-capita health care spending, in absolute value and as a fraction of gross domestic product, yet our nation's health, particularly our children's health, does not rank as highly. Reflecting on this issue and on Dr Gitterman's data that showed a decline in NIH spending on child health research, Dr Dover suggested that increased spending on child health research would not only improve child health but also decrease the expenditure for costly adult-onset diseases that have their origins in the pediatric age group. He noted both past and present acceptance of the concept that healthy children equal healthy adults and noted as examples the prevention of infectious diseases through vaccines, the prevention of single-gene disorders that can lead to chronic adult diseases, successful counseling against high-risk behavior, screening for environmental toxins, and protection of the elderly from infections through "herd immunity." Dr Dover summarized the paradigm of investment in research for preemption and prevention of adult-onset diseases, outlined by Dr Elias Zerhouni, former director of the NIH, in his presentation to Congress during the NIH appropriations hearings before Congress in 2007 (fiscal-year 2008 budget request witness appearance before the House and Senate Subcommittees on Labor, Health and Human Services, Education Appropriations, Elias A. Zerhouni, MD, Director, NIH, March 6 and 19, 2007; ref 8) (Fig 2). Prevention in the pediatric age group of adult-onset disorders (eg, cardiovascular diseases including coronary artery disease and hypertension, obesity, type 2 diabetes, adult cancers, certain psychiatric disorders, and even Alzheimer disease) through increased research investments in pediatrics will reduce health care costs exponentially more than trying to continue to treat these disorders after they clinically appear in adults.

This approach sets the stage for how pediatric research can lead to healthier adults through research focused on genetic susceptibility to diseases. Future research aimed at finding specific genes or networks of genes that directly link to and/or cause specific diseases would allow an individualized approach to prevention and therapy. Research also should focus on how the environment influences the expression of these genes, thereby allowing detection of susceptibility to adult diseases long before they appear clinically. Dr Dover reviewed the concept that the human genome has evolved in a manner that ensures sufficient variability in the genetic code and flexibility in the controls of gene expression such that the human species can readily adapt to changes in the environment. The varieties of adaptations that are made over evolutionary time are focused on 2 absolute necessities. First, the species must produce healthy individuals able to adapt as a developing fetus to the in utero environment and as an infant to the immediate postnatal environment (successful reproduction). Second, these children must grow old enough to also have children and to protect their young 
(propagation of the species). Thus, the susceptibility to adult-onset disorders is a byproduct of evolution, which is essentially blind to the maladaptive consequences of older age.

Dr Dover reflected on the work of Barker, originator of the fetal-origins-of-adult-disease hypothesis. Barker first noted that early death caused by cardiovascular disease was inversely related to birth weight.9 Fetal growth is primarily the result of environmental factors, including prepregnancy weight, maternal nutrition, and plasma nutrient substrate composition and maternal exposure to toxins in the environment. Cigarette smoking, for example, is a major cause of fetal growth restriction, through a variety of direct toxicity mechanisms and impaired maternal health, as much as or more so than genetic growth potential.10 More recent research by Barker and his now many followers has revealed additional risks from fetal growth restriction of later-life insulin resistance, obesity, pancreatic insulin-secretion failure, and type 2 diabetes.11-13 Such "adult-onset disorders" are moving into the school-age population, where they are exacerbated by societal trends toward high-calorie (particularly sugar) diets and sedentary lifestyle. Paradoxically, high birth weights $(>5 \mathrm{~kg})$ increase risks of pediatric and adult-onset cancers. 14

Dr Dover then demonstrated how pediatricians can manipulate gene expression early in infancy to affect risks for later-life onset of adult diseases. He commented specifically on the studies from Lucas's group in the United Kingdom, which has strikingly shown that clinical interventions by neonatologists and pediatricians to induce more rapid growth in preterm or small-for-gestational-age infants lead to impaired insulin sensitivity in adolescents and higher blood pressure.15,16 Adapting diet and exercise regimens to prevent or ameliorate such rapid growth is an excellent target, therefore, for pediatricians to positively influence the risk of later-life obesity, hypertension, and type 2 diabetes.

It has become apparent that environmental factors during prenatal and postnatal life can have profound effects on the programming of intracellular signals, cell-cell interactions, and metabolic pathways. These adaptations of the human genome can affect the onset of both adult and childhood disorders. One might imagine that perinatologists and pediatricians may be able to screen infants for increased risks to diseases by whole-genome analysis, searching for variation in the genetic code and searching the epigenome for variations in gene expression. The case for investment in pediatric research, therefore, is strong.

\section{SUMMARY AND CONCLUSIONS}

Pediatric-research funding has increased considerably less than the overall NIH budget, decreasing from $13.1 \%$ in 1993 to $11.3 \%$ in 2005; this declining trend has continued and worsened over the past 4 years. Furthermore, Congress has not yet appropriated new funds for the bipartisan PRI that was central in the Children's Health Act of 2000, and the NIH has not, as a result, shifted its overall research support in favor of funding for pediatric research. As a result, pediatric research is losing ground, and children, not just pediatric scientists, will lose out on the critical need for new preventive measures and treatments of the many diseases that they suffer. This decline in research funding is occurring despite a large portfolio of research and training programs that are supported by the NICHD. New initiatives for congressional support for child health research, such as the Pediatric Research Consortium Act, are necessary to start providing the infrastructure to expand pediatric research throughout the United States. Furthermore, research into the causes, preventions, and treatments of diseases that begin very early in life will have a profound, lifelong impact on disease burden and financial costs. Learning more through fundamental research about the causes of intrauterine growth restriction, preterm birth, obesity, diabetes, inflammation, allergy, genetic diseases, host-pathogen interactions, and how essential nutrients and unnatural toxins affect brain development, among other examples, will lead to the promise 
of improved health, not just in childhood but also throughout the life of the individual and on to future generations. Such efforts to improve child health should begin before delivery in conjunction with our obstetric colleagues while recognizing that a healthy mother has a much better chance of producing a healthy infant, child, and adolescent and a future healthy adult. The principal point is that pediatric research has a much greater potential to preempt and prevent the lifelong burden and financial cost of diseases than investigations directed at problems that begin later in life.

\section{ABBREVIATIONS}

$\begin{array}{ll}\text { NIH } & \text { National Institutes of Health } \\ \text { PRI } & \text { Pediatric Research Initiative } \\ \text { NICHD } & \text { Eunice Kennedy Shriver National Institute of Child Health and Development } \\ \text { PPRU } & \text { Pediatric Pharmacology Research Unit } \\ \text { CTSA } & \text { Clinical Translational Science Award } \\ \text { NCS } & \text { National Children's Study }\end{array}$

\section{REFERENCES}

1. Gitterman DP, Greenwood RS, Kocis KC, Mayes BR, McKethan AN. Did a rising tide lift all boats? The NIH budget and pediatric research portfolio. Health Aff (Millwood). 2004; 23(5):113-124. [PubMed: 15371375]

2. Gitterman DP, Hay WW Jr. That sinking feeling, again? The state of National Institutes of Health pediatric research funding, fiscal year 1992-2010. Pediatr Res. 2008; 64(5):462-469. [PubMed: 18787420]

3. Landro L. For severely ill children, a dearth of doctors: lower salaries, reimbursement rates create shortfall of specialists. Wall Street Journal. 2010 Jan 20. Available at: http://online.wsj.com/article/ SB10001424052748703652104574652311818328216.html.

4. Hirschfeld S, Ho PT, Smith M, Pazdur R. Regulatory approvals of pediatric oncology drugs: previous experience and new initiatives. J Clin Oncol. 2003; 21(6):1066-1073. [PubMed: 12637472]

5. Gordon EJ, Yamokoski AH, Kodish E. Children, research, and guinea pigs: reflections on a metaphor. IRB. 2006; 28(5):12-19.

6. Levi RB, Marsick R, Drotar D, Kodish ED. Diagnosis, disclosure, and informed consent: learning from parents of children with cancer. J Pediatr Hematol Oncol. 2000; 22(1):3-12. [PubMed: 10695815]

7. Halfon N, DuPlessis H, Inkelas M. Transforming the U.S. child health system: "business as usual" will not help us achieve the health care system that our children deserve. Health Aff (Millwood). 2007; 26(2):315-330. [PubMed: 17339658]

8. Hay WW Jr. American Pediatric Society presidential address 2008: research in early life—benefit and promise. Pediatr Res. 2009; 65(1):117-122. [PubMed: 18787504]

9. Barker DJ, Winter PD, Osmond C, Margetts B, Simmonds SJ. Weight in infancy and death from ischaemic heart disease. Lancet. 1989; 2(8663):577-580. [PubMed: 2570282]

10. Kramer MS. Determinants of low birth weight: methodological assessment and meta-analysis. Bull World Health Organ. 1987; 65(5):663-737. [PubMed: 3322602]

11. Frankel S, Elwood P, Sweetnam P, Yarnell J, Smith GD. Birthweight, body-mass index in middle age, and incident coronary heart disease. Lancet. 1996; 348(9040):1478-1480. [PubMed: 8942776]

12. Thompson JN. Fetal nutrition and adult hypertension, diabetes, obesity, and coronary artery disease. Neonatal Netw. 2007; 26(4):235-240. [PubMed: 17710957] 
13. Baker JL, Olsen LW, Sorensen TI. Weight at birth and all-cause mortality in adulthood. Epidemiology. 2008; 19(2):197-203. [PubMed: 18300695]

14. Ahlgren M, Wohlfahrt J, Olsen LW, Sorensen TI, Melbye M. Birth weight and risk of cancer. Cancer. 2007; 110(2):412-419. [PubMed: 17538980]

15. Singhal A, Fewtrell M, Cole TJ, Lucas A. Low nutrient intake and early growth for later insulin resistance in adolescents born preterm. Lancet. 2003; 361(9363):1089-1097. [PubMed: 12672313]

16. Singhal A, Cole TJ, Fewtrell M, et al. Promotion of faster weight gain in infants born small for gestational age: is there an adverse effect on later blood pressure? Circulation. 2007; 115(2):213220. [PubMed: 17179023] 


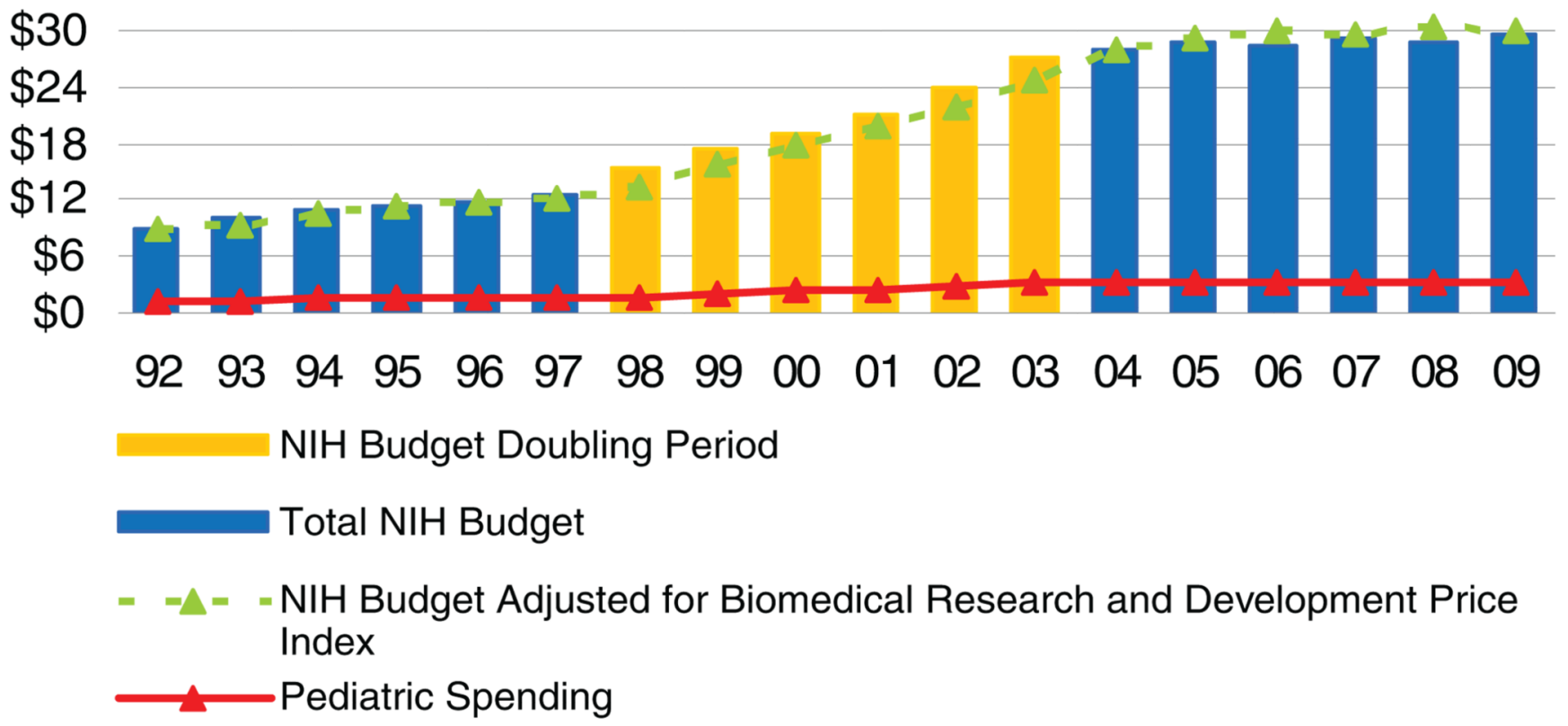

FIGURE 1.

NIH budget and pediatric-research portfolio, fiscal-year 1992-2009 (in billions).1,2 Source: NIH Office of the Budget. Note: The NIH defines pediatric research as "studies in all categories of biomedical research (basic, clinical, epidemiologic, behavioral, prevention, treatment, diagnosis, as well as outcomes and health services) that relate to diseases, conditions, or the health/development of neonates, infants, children, and adolescents up to the age of 21. (Reproduced with permission from Gitterman DP, Hay WW Jr. Pediatr Res. 2008;64[5]:464.) 


\section{Time of onset}

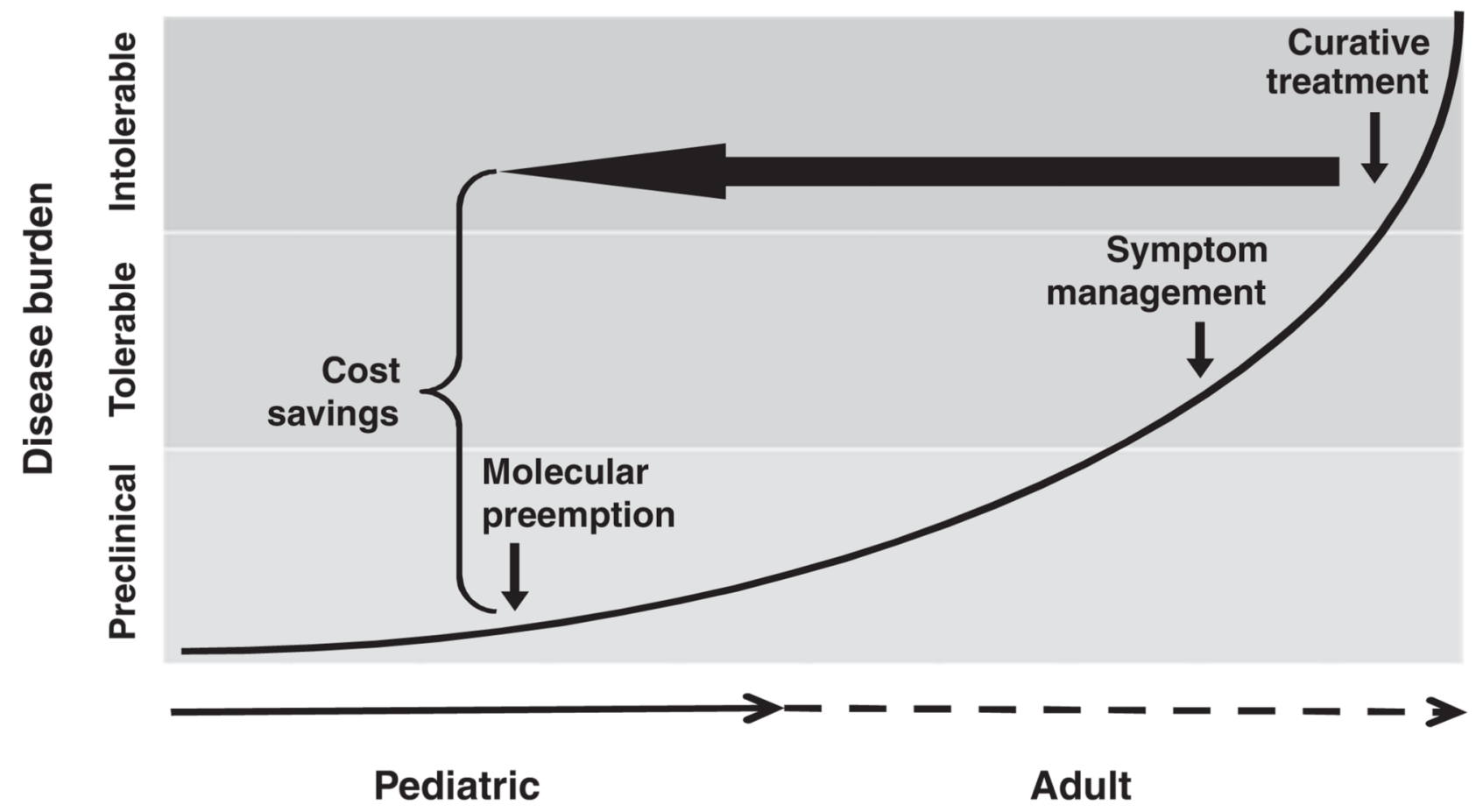

FIGURE 2.

Investment in pediatric research to identify and treat adult-onset diseases in childhood leads to significant cost savings and reduced burden of disease (fiscal-year 2008 budget request witness appearance before the House and Senate Subcommittees on Labor, Health and Human Services, Education Appropriations, Elias A. Zerhouni, MD, Director, NIH, March 6 and 19, 2007; Adapted from ref 8). 
TABLE 1

NICHD Network and Center Programs Targeted Directly to Pediatric Research

\begin{tabular}{l} 
Autism Centers of Excellence \\
Community and Child Health \\
Intellectual and Developmental Disabilities Research Centers \\
Muscular Dystrophy Centers \\
Rare Diseases Centers \\
Maternal-Fetal Medicine Network \\
Neonatal Medicine Network \\
Pediatric Critical Care Network \\
Adolescent HIV Medicine Trials Network \\
DirectNet and TrialNet (diabetes) \\
Genomics, Proteomics, and Prematurity \\
Global Network for Women and Children's Health \\
Learning Disabilities Centers \\
Pediatric Pharmacology \\
Stillbirth Network \\
\hline
\end{tabular}

